\title{
Investigation of Mechanical Behaviour on Composites of Al6063 Alloy with Silicon, Graphite and Fly Ash
}

\author{
M. Loganathan ${ }^{1, *}$, S. Dinesh ${ }^{2}$, V. Vijayan ${ }^{2}$, T. Karuppusamy ${ }^{2}$ and S. Rajkumar ${ }^{3}$ \\ ${ }^{1}$ Department of Mechanical Engineering, M.Kumarasamy College of Engineering, Karur, Tamilnadu 639113, India \\ ${ }^{2}$ Department of Mechanical Engineering, K.Ramakrishnan College of Technology, Tiruchirappalli, Tamilnadu 621112, India \\ ${ }^{3}$ Departmant of Mechanical Engineering, Hawassa Institute of Technology, Hawassa, Ethiopia
}

Corresponding Author Email: logukrr@gmail.com

\begin{abstract}
In this investigation depend on composites of Al6063 alloy mechanical properties enhancement by mixing the Silicon (Si), Graphite (Gr) and Fly ash. In this case four combinations of specimens were created for investigation. 90\% of Al6063 alloy and 5\% of Silicon maintained for all the specimens. Graphite used from $1 \%$ to $4 \%$ with one percentage of incremental and Fly ash from thermal power stations added from $4 \%$ to $1 \%$ with one percentage of decrement in composite composition. Ultimate tensile strength, yield strength, percentage of elongation and hardness were mainly focused to study.
\end{abstract}

Keywords: Al6063, silicon, graphite, fly ash, mechanical properties Received: November-29-2019, Accepted: January-19-2020, https://doi.org/10.14447/jnmes.v23i1.a07

\section{INTRODUCTION}

Enhancement of desirable mechanical properties of materials focused in many of the researches. Hybrid composites of aluminium hold a variety of applications under critical working atmospheres [1]. The Al-hybrid composites post better mechanical properties than the base material and conventional composites. The risk associated with Al-hybrid composites lies with selection of appropriate reinforcement particles and there proportions [2]. The waste materials that are derived from industrial process and agricultural waste can be used for making Hybrid AMC's. The combination of added material to the base material can moderate the properties of the base material depend on the added material properties [3]. Need of number of properties leads to increase the added materials list in the base material [4]. Desired properties can be achieved by varying the percentage of the adding materials in the base material. In this investigation Silicon, graphite and fly ash content mingled with the Al6063 aluminium alloy with percentage of weight basis. The hardness of the hybrid composite has been increased by $11 \%$ due to addition of the steel particles in proportions of weight ranging between $4 \%$ and $8 \%[5,6]$.

Also, the tensile strength increased with addition of steel. But, the mechanical properties decreased increase in $\mathrm{SiC}$ content and with increase in graphite [7]. Aluminium based hybrid composites with varying concentrations of the steel, steel-SiC mix and Steel-graphite mix showed better mechanical properties when compared to the base material. With addition of $\mathrm{B} 4 \mathrm{C}$ and $\mathrm{MoS} 2$ to $\mathrm{Al} 2219$, an increase in density was achieved when compared to the base material [8]. It also proved that Stir Casting Method can be used for making aluminium based hybrid composites as not much difference in densities were recorded between the base material and the composites that were casted. An increase in micro hardness and decrease in tensile strength was also recorded with the reinforcement of the $\mathrm{B} 4 \mathrm{C}$ and $\mathrm{MoS} 2$ particles to the base material [9].

Addition of B4C in increasing concentrations elevated the micro hardness of the developed composite. The decrease in yield strength and the tensile strength was due to the increase of the MoS2 particles. The hybrid AMC developed by reinforcing MWCNT and $\mathrm{SiC}$ was characterised with improved hardness and wear resistance. The wear resistance was improved with increase in \% weight contribution of MWCNT [10-12]. Reinforcement of SiC and TiB2 increases the hardness of the developed composite. Further, the tensile strength of developed composites has decreased with the addition of TiB2. Also, addition of TiB2 has improved the wear resistance of the drastically when compared to base alloy. Formation of cluster was identified the when the developed composite surface. This is due to the increased reinforcement of TiB2 with aluminium alloy [13].

Hybrid Composites of Al reinforced with $\mathrm{SiC}$ and RHA particles of equal concentrations is characterised with low densities. This results in increase in tensile strength with the increase in weight proportions of the reinforcement particles $[14,15]$. The elongation behaviour of the developed composite has decreased as the material is of ductile in nature. Age hardening was seen with the developed composites at very lower time leading to hard surface formation. Complicated shapes can be made economically by using stir casting method with regard to hybrid composites [16-18]. Fiber can be evenly distributed uniformly with high volume of fiber using diffusion bonding. But this bonding strategy is not suitable for making complicated and intricate shapes [19]. Finer grain sizes and lower segregation can be obtained in the surfaces of the developed composites with the help of deposition. Although it produces better grain sizes, the major problem associated with this process is its poor reinforcement capacity and its high cost. Also, only simple shapes can be made with this process [20]. Fly ash reinforced AA 6063 shows decrease 
in density of the composite. This increases the porosity as well as the hardness of the developed composites. Also, the impact strength of the Fly ash reinforced composite increases with the increased proportion than the base alloy [21].

Based on the literature survey, the hybrid composites post better mechanical properties than the conventional composites and the alloys. The works aims at formulation and testing of hybrid composite by reinforcing the graphite, silicon and fly ash. The fly ash was selected for its property to increase the hardness of developed composite and its ability to decrease the density even though it produces porosity. Graphite has been selected for its ability to increase the tensile strength of the composites developed. Si tends to increase the density of the composite. Stir casting method was used to make the hybrid composite.

\section{EXPERIMENTAL PROCEDURE}

Table 1. Composition details of composites

\begin{tabular}{ccccc}
\hline Composite number & Al6063 & Silicon & Graphite & Fly ash \\
\hline 1 & $90 \%$ & $5 \%$ & $1 \%$ & $4 \%$ \\
2 & $90 \%$ & $5 \%$ & $2 \%$ & $3 \%$ \\
3 & $90 \%$ & $5 \%$ & $3 \%$ & $2 \%$ \\
4 & $90 \%$ & $5 \%$ & $4 \%$ & $1 \%$ \\
\hline
\end{tabular}

Here composites created with the proportions based on the table 1 by normal stir casting method. In all composites Al6063 maintained as 90 percentage and Silicon as 5\%. The variation of percentage of remaining 5\% is created by Graphite and Fly ash. Both of these two material variations create as per table 1 in each and every specimen. The prepared specimens were formed as per the needs of the mechanical property related tests like ultimate tensile strength, yield strength, percentage of elongation and hardness for conducting tests in smooth manner. UTM machine and Brinell hardness machine were used to measure the corresponding outcomes of the specimens. Al6063 and Si are same for all the specimens so the results describe about the participation of Graphite and fly ash content level in the composite.

\section{RESULT AND DISCUSSION}

Table 2 shows the experimental results. In Figure 1 obviously shows the measured ultimate tensile strength values in $\mathrm{MPa}$ which increased with respect to the increasing percentage of Graphite and decreasing percentage of fly ash in the four combinations of composite. The lowest Ultimate strength was encountered for sample 1 . The maximum value was recorded as $277 \mathrm{Mpa}$. Increase in graphite has increased the ultimate strength by $6.86 \%$. This indicates the increase in ductility of the developed composite. Also, it is evident that the fly ash has also improved the ultimate tensile strength of the composites. The addition of fly ash has reduced the density of the composite. But due to the addition of graphite the hardness has also increased. A linear increase in ultimate strength is recorded for increasing graphite percentage and reduced fly ash.

The yield strength is normally found with ductile materials within the elastic limit. Normally the yield strength of a material is very much lesser than the ultimate strength. Here, the above said characteristics are being proved with the developed composite. It is observed that, the maximum yield strength is obtained for the composites with $3 \%$ graphite and $2 \%$ fly ash as shown in Figure 2. The reason for increased yield strength is because of the balanced reinforcement of the graphite and fly ash at respective levels. The ability of flyash to reduce the density has compensated the ability of graphite to increase the density of the developed composite. The AMC developed has the lowest yielding capacity when $1 \%$ of graphite and $4 \%$ of fly ash is reinforced on the surface of the Al6063 alloy. Due to reduced percentage graphite and maximum fly ash reinforcement, the yield strength has reduced as the fly ash has the ability to reduce the density. A linear increase in yield strength was noted with simultaneous increase in graphite percentage and reducing fly ash percentage upto a reinforcement level of 3\% graphite and $2 \%$ of fly ash. The yield strength has reduced beyond the above notified percentage of graphite and reduced level of fly ash below 1\%. This has been noted in sample 4 . A $10.68 \%$ of increase in yield stress has been achieved when compared to the lowest that was recorded with sample 1.

Table 2. Experimental Results

\begin{tabular}{ccccc}
\hline Composite number & \% of Elongation & Ultimate Tensile Strength (Mpa) & Yield Strength (Mpa) & Brinell Hardness (BHN) \\
\hline 1 & 9 & 258 & 163 & 84 \\
2 & 8.74 & 263 & 170 & 89 \\
3 & 8.13 & 270 & 182.5 & 91 \\
4 & 8.8 & 277 & 165 & 86 \\
\hline
\end{tabular}

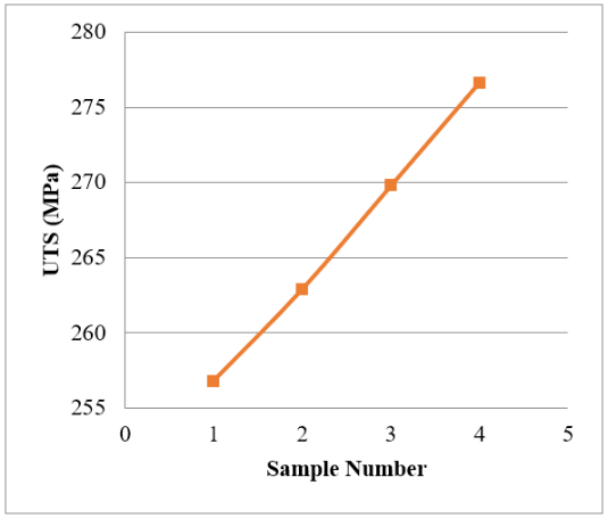

Figure 1. Ultimate tensile strength

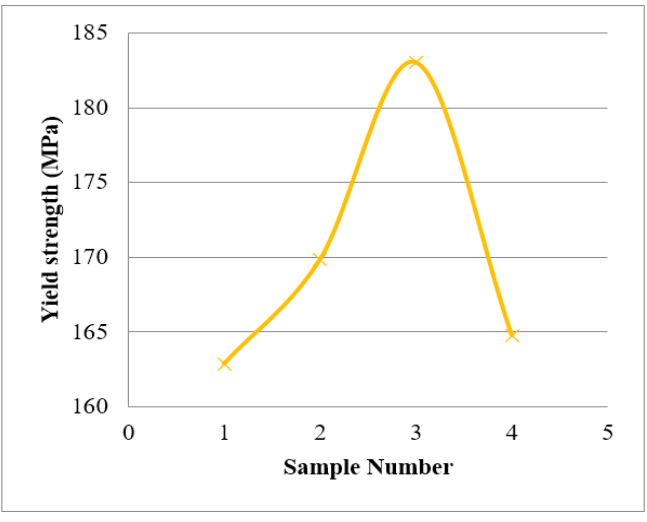

Figure 2. Yield strength 


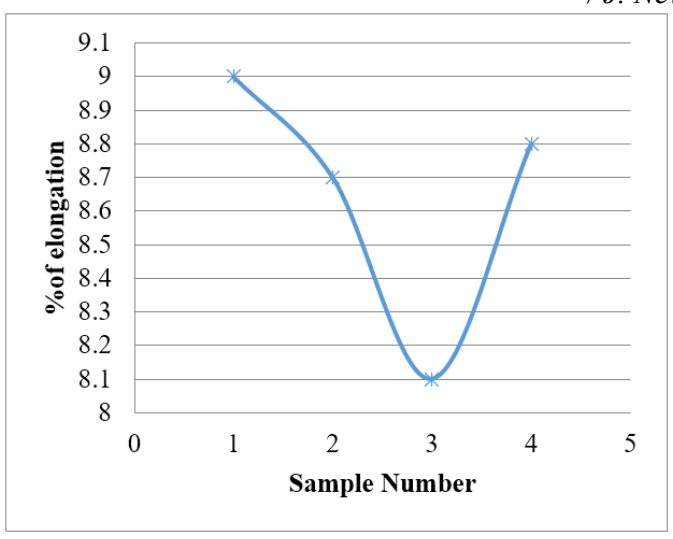

Figure 3. Percentage of elongation

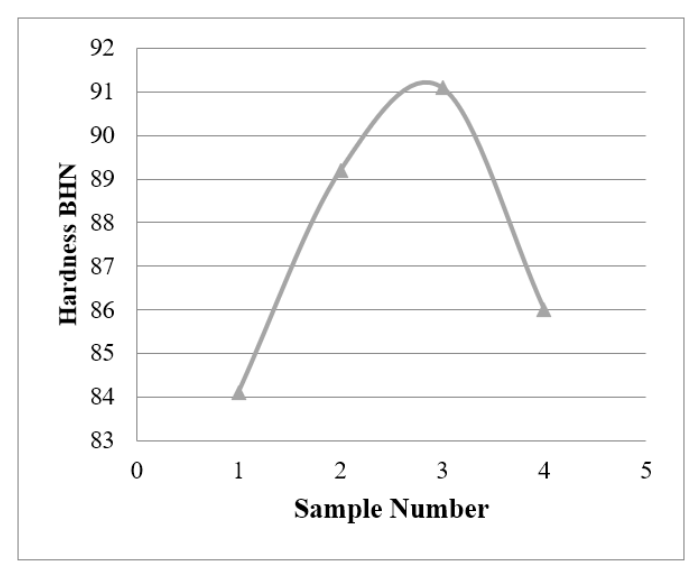

Figure 4. Hardness

The effect of simultaneous increase in graphite and reduction in fly ash reinforcement over the percentage of elongation has been elaborated in Figure 3. It is noted that, the percentage of elongation has reduced with the simultaneous increase in graphite and reduction in fly ash reinforcement to Al 6063 alloy in exponential fashion. The elongation behaviour has reduced in linear mode up to $3 \%$ graphite and $2 \%$ fly ash reinforcement. Due to the increased density of the sample 4 in comparison with sample 1 and 2, the percentage of elongation has increased. This proves that the ductility of the material has been altered by the reinforcements made on Al 6063 alloy. Also, the toughness of the material has also been altered which is indirectly proportional to the ductility of the developed AMC. The elongation characterises was found to high with sample 1 which had $1 \%$ graphite and $4 \%$ fly ash reinforced to the alloy. A $9.67 \%$ of increase in elongation has been achieved when compared to the lowest percentage of elongation that was recorded with sample 3.

The hardness of the AMC's has varied exponentially. The maximum hardness has been recorded with the same level of reinforcement of the sample that had the maximum yield strength. It proves that, yield strength and the hardness of the developed AMC are directly proportional. This resembles with the characteristics of the metal which have higher weight that than the developed AMC. It is noted that the minimum hardness was found with the sample 4 which has $1 \%$ of fly ash and $3 \%$ of graphite reinforced over the alloy. Due the ability of fly ash to reduce the density of the material, the hardness has reduced for sample 4. A linear increase in hardness was noted with simultaneous increase in graphite percentage and reducing fly ash percentage up to a reinforcement level of $3 \%$ graphite and $2 \%$ of fly ash as shown in Figure 4. A $3.84 \%$ of increase in hardness has been achieved when compared to the lowest hardness that was recorded with sample 1 .

Reduced ultimate tensile strength related to increasing percentage of Fly ash with other composition in composites was noted clearly. Accelerated and decelerated measured yield strength values plot related to increasing percentage of Fly ash. The incremental percentage of elongation related to increasing percentage of Fly ash mentioned observably.

\section{CONCLUSION}

In this investigation of mechanical behavior on A16063 alloy with Silicon, Graphite and Fly ash used composites bring into being the following conclusions.

$\checkmark$ The Ultimate tensile strength values of specimens directly proportional to the percentage of Graphite and inversely proportional to percentage of fly ash in the total percentage.

$\checkmark$ Maximum yield strength obtained in of specimen with $3 \%$ of graphite and $2 \%$ of fly ash.

$\checkmark$ Maximum amount of graphite and fly ash leads to reduce the yield strength.

$\checkmark$ Percentage of elongation decreased up to augmentation level $3 \%$ of graphite and decrement level of fly ash with $4 \%$ to $2 \%$.

$\checkmark$ Maximum mean hardness reached at specimen with $3 \%$ of graphite and $2 \%$ of fly ash.

\section{REFERENCES}

[1] Sathish, T., Karthick, S. (2020). Wear behaviour analysis on aluminium alloy 7050 with reinforced $\mathrm{SiC}$ through taguchi approach. Journal of Materials Research and Technology, $9(3)$ : $\quad 3481-3487$. https://doi.org/10.1016/j.jmrt.2020.01.085

[2] Sathish, T., Sabarirajan, N., Karthick, S. (2020). Machining parameters optimization of Aluminium Alloy 6063 with reinforcement of $\mathrm{SiC}$ composites. Materials Today: https://doi.org/10.1016/j.matpr.2019.12.085

[3] Muthukumar, K., Sabariraj, R.V., Kumar, S.D., Sathish, T. (2020). Investigation of thermal conductivity and thermal resistance analysis on different combination of natural fiber composites of Banana, Pineapple and Jute. Materials Today: Proceedings, 21: 976-980. https://doi.org/10.1016/j.matpr.2019.09.140

[4] Sathish, T. (2018). BONN Technique: Tribological Properties Predictor for Plasma Nitrided 316L Stainless Steel. Materials Today: Proceedings, 5(6): 14545-14552. https://doi.org/10.1016/j.matpr.2018.03.044

[5] Sathish, T. (2018). GAC-ANN Technique for Prediction of Spring Back Effect in Wipe Bending Process of Sheet Metal. Materials Today: Proceedings, 5(6): 14448-14457. https://doi.org/10.1016/j.matpr.2018.03.031

[6] Sathish, T., Chandramohan, D., Vijayan, V., Sebastian, P.J. (2019). Investigation on microstructural and mechanical properties of $\mathrm{Cu}$ reinforced with Sic composites prepared by microwave sintering process. Journal of New Materials for Electrochemical Systems, 22(1): 5-9. https://doi.org/10.14447/jnmes.v22i1.a02 
[7] Sathish, T., Saravanan, S., Vijayan, V. (2019). Effect of reinforced aluminium alloy LM30 with pure ceramic particles to evaluate hardness and wear properties. Materials Research Innovations, 24(3): 129-132. https://doi.org/10.1080/14328917.2019.1614321

[8] Parameswaran, P., Rameshbabu, A.M., Krishnan, G.N., Yogeshwaran, R., Ramkumar, R. (2018). Study of the corrosion properties in a hot forged $\mathrm{Cu}-\mathrm{Al}-\mathrm{Ni}$ alloy with added Cr. Journal of the Mechanical Behavior of Materials, 27(3-4). https://doi.org/10.1515/jmbm-20180016

[9] Kumar, P.R., Navaneethakrishnan, G., Umanath, K. (2018). Experimental analysis of glass fibre-sisal reinforced composite material. International Journal of Mechanical and Production Engineering Research and Development, 8: 943.

[10] Kumar, P.R., Navaneethakrishnan, G., Umanath, K. (2018). Experimental investigation on mechanical properties of hybrid composite material. International Journal of Mechanical and Production Engineering Research and Development, 8: 1264.

[11] Navaneethakrishnan, G., Selvam, V., Saravanan, C. (2015). Effect of Cnts-Fe2o3 hybrids on mechanical studies of glass fibre/epoxy nanocomposites. Journal of Chemical and Pharmaceutical Sciences, 974: 199.

[12] Saravanan, C., Subramanian, K., Anandakrishnan, V., Sathish, S. (2018). Tribological behavior of AA7075TiC composites by powder metallurgy. Industrial Lubrication and Tribology. https://doi.org/10.1108/ILT10-2017-0312

[13] Sinteza, I., Kompozitov, M. (2018). Synthesis and Forming Behaviour of AA7075-TiC Powder-Metallurgy Composites. $\quad$ Synthesis, 809: 812. https://doi.org/10.17222/mit.2017.189

[14] Saravanan, C., Subramanian, K., Krishnan, V.A., Narayanan, R.S. (2015). Effect of particulate reinforced aluminium metal matrix composite-a review. Mechanics and Mechanical Engineering, 19(1): 23-30.
[15] Garg, P., Jamwal, A., Kumar, D., Sadasivuni, K.K., Hussain, C.M., Gupta, P. (2019). Advance research progresses in aluminium matrix composites: manufacturing \& applications. Journal of Materials Research and Technology, 8(5): 4924-4939. https://doi.org/10.1016/j.jmrt.2019.06.028

[16] Padmavathi, K.R., Ramakrishnan, R. (2014). Tribological behaviour of aluminium hybrid metal matrix composite. Procedia Engineering, 97: 660-667. https://doi.org/10.1016/j.proeng.2014.12.295

[17] Alaneme, K.K., Fajemisin, A.V., Maledi, N.B. (2019). Development of aluminium-based composites reinforced with steel and graphite particles: structural, mechanical and wear characterization. Journal of Materials Research and Technology, $8(1)$ : 670-682. https://doi.org/10.1016/j.jmrt.2018.04.019

[18] James, S.J., Venkatesan, K., Kuppan, P., Ramanujam, R. (2014). Hybrid aluminium metal matrix composite reinforced with $\mathrm{SiC}$ and TiB2. Procedia Engineering, 97: 1018-1026. https://doi.org/10.1016/j.proeng.2014.12.379

[19] Bodunrin, M.O., Alaneme, K.K., Chown, L.H. (2015). Aluminium matrix hybrid composites: a review of reinforcement philosophies; mechanical, corrosion and tribological characteristics. Journal of Materials Research and Technology, 4(4): 434-445. https://doi.org/10.1016/j.jmrt.2015.05.003

[20] Alaneme, K.K., Olubambi, P.A. (2013). Corrosion and wear behaviour of rice husk ash-Alumina reinforced Al-Mg-Si alloy matrix hybrid composites. Journal of Materials Research and Technology, 2(2): 188-194. https://doi.org/10.1016/j.jmrt.2013.02.005

[21] Prasad, D.S., Shoba, C., Ramanaiah, N. (2014). Investigations on mechanical properties of aluminum hybrid composites. Journal of Materials Research and Technology, 3(1): 79-85. https://doi.org/10.1016/j.jmrt.2013.11.002 